\title{
Experimental and Theoretical Studies of the Vibrational and Electronic Properties of (2E)-2-[3-(1H-imidazol-1-yl)-1-phenyl- propylidene]- $N$-phenylhydrazinecarboxamide: An Anticonvulsant Agent
}

Munusamy Govindarajan ${ }^{1,2}$, Ali S. Abdelhameed ${ }^{3}$, Abdulaziz A. Al-Saadi ${ }^{4}$ and

Mohamed I. Attia ${ }^{3,5 *}$

1 Department of Physics, Bharathidasan Government College for Women (BGCW), Puducherry 605003, India; E-Mail: govindarajan64@gmail.com

2 Department of Physics, Avvaiyar Government College for Women (AGCW), Karaikal Puducherry 609602, India

3 Department of Pharmaceutical Chemistry, College of Pharmacy, King Saud University, P.O. Box 2457, Riyadh 11451, Saudi Arabia; E-Mail: asaber@ksu.edu.sa

4 Department of Chemistry, King Fahd University of Petroleum and Minerals, Dhahran 31261, Saudi Arabia; E-Mail: asaadi@kfupm.edu.sa

5 Medicinal and Pharmaceutical Chemistry Department, Pharmaceutical and Drug Industries Research Division, National Research Centre, Dokki, Giza 12622, Egypt

* Author to whom correspondence should be addressed; E-Mail: mattia@ksu.edu.sa; Tel.: +966-114677337; Fax: +966-114676220.

Academic Editors: Helmut Martin Hügel and Totaro Imasaka Received: 29 August 2015 / Accepted: 20 October 2015 / Published: 29 October 2015

Abstract: In the current investigation, the molecular structure of the anticonvulsant agent (2E)-2-[3-(1H-imidazol-1-yl)-1-phenylpropylidene]- $N$-phenylhydrazinecarboxamide ((2E)-HIPC) was theoretically modelled using ab initio Hartree-Fock (HF) and density functional theory (DFT/B3LYP) calculations. The Fourier transform (FT) infrared and FT-Raman spectra of (2E)-HIPC were also recorded, and the observed bands were assigned to the vibrational normal modes. The main functional groups were identified via vibrational analysis, and their absorption bands were assigned. A comparative analysis was performed for the computed and experimental results. Subtle differences were observed between the calculated and experimental UV-Vis spectra. Time-dependent density functional theory (TD-DFT) excitation energies were calculated for five excited electronic 
states. The calculations were applied to simulate the spectra of (2E)-HIPC, and these simulated spectra exhibited excellent agreement with the experimental spectra. The DFT/B3LYP/6-311++G(d,p) method, after scaling, exhibited better agreement with the experimental values than the results obtained by the HF method. The energy, oscillator strength, and wavelength computed by TD-DFT (IEFPCM) are consistent with the experimental results. The molecular electrostatic potential (MEP) and frontier molecular orbitals (HOMO-LUMO) were also determined to enable prediction of the structural changes and reactive sites. Mulliken population charges of the title molecule were also calculated in the gas phase. The NMR chemical shifts $\left({ }^{13} \mathrm{C}\right.$ and $\left.{ }^{1} \mathrm{H}\right)$ were calculated using the gauge-including atomic orbital method and the B3LYP/6-311++G(d,p) approach and were compared with the experimental values.

Keywords: (2E)-HIPC; FT-IR; FT-Raman; DFT/B3LYP; HF

\section{Introduction}

Epilepsy as a disease can be described as a group of serious brain disorders affecting people of all ages. It is characterized by the onset of spontaneous convulsive and non-convulsive seizures. Epilepsy affects approximately 50 million people with a high prevalence in the first decade of life and in individuals more than 60 years old [1,2]. Conventional antiepileptic agents (i.e., phenytoin and carbamazepine) and recent antiepileptic drugs (i.e., gabapentin, vigabatrin, remacemide, and loreclezole) are clinically effective for different seizure types. However, only $50 \%$ of sufferers are adequately treated with the currently available antiepileptic drugs (AEDs), and a few AEDs have severe side effects [3-7]. Therefore, the development of safer and more effective AEDs is necessary. The rational design and discovery of new antiepileptics are difficult due to incomplete data concerning the molecular modeling pathway of human epilepsy and the sophisticated mechanism of action for the majority of antiepileptic drugs [8]. Therefore, a ligand-based approach is one of the most important strategies for the development of new AEDs using the available biological information from well known and novel drugs. (2E)-2-[3-(1H-imidazol-1-yl)-1-phenylpropylidene]- $N$-phenylhydrazinecarboxamide ( $(2 E)$-HIPC) is a hybrid structure incorporating both imidazole and arylsemicarbazone moieties that act as pharmacophore scaffolds in some candidate anticonvulsants $[9,10]$. This compound has exhibited anticonvulsant activity with $16 \%$ seizure protection at a dose level of $750 \mu \mathrm{mol} / \mathrm{kg}$ in a subcutaneous pentylenetetrazole (scPTZ) screen with no neurotoxicity [11].

The molecular structure of (2E)-HIPC has not previously been explored using computational methods. Therefore, we used ab initio Hartree-Fock (HF) and density functional theory (DFT/B3LYP) approaches to model the molecular structure of $(2 E)$-HIPC. DFT/B3LYP/6-311++G(d,p) is a hybrid DFT standard computational method that gave sufficiently accurate results for organic molecules without consuming significant amounts of computing resources. Fourier transform infrared (FT-IR) and Raman spectra were also collected, and the data were compared with the computed spectra. The molecular electrostatic potential (MEP) and frontier molecular orbitals (HOMO-LUMO) of (2E)-HIPC were computed to predict the structural changes and reactive sites. In addition, the NMR 
$\left({ }^{13} \mathrm{C}\right.$ and $\left.{ }^{1} \mathrm{H}\right)$ chemical shifts of the title molecule were computed by the gauge-including atomic orbital method using B3LYP/6-311++G(d,p) calculations, and the theoretical results were compared with the experimental values.

\section{Experimental Section}

\subsection{General}

The melting point was determined on a Gallenkamp melting point apparatus and is uncorrected. The FT-IR spectrum was obtained using $\mathrm{KBr}$ pellets on a DR/Jasco FT-IR 6300 spectrometer with a spectral resolution of $2 \mathrm{~cm}^{-1}$ (JASCO Inc., Easton, MD, USA). The FT-Raman spectrum was recorded on a Bruker RFS 100/s, Ettlingen, Germany. Excitation wavelength was $1064 \mathrm{~nm}$ with a maximal power of $150 \mathrm{~mW}$ and the emission of Nd:YAG laser (Goettingen, Germany) was used. The measurements were performed on solid samples. NMR spectra were measured in DMSO- $d_{6}$ on a Bruker NMR spectrometer (Ettlingen, Germany) operating at $500 \mathrm{MHz}$ for ${ }^{1} \mathrm{H}$ and $125.76 \mathrm{MHz}$ for ${ }^{13} \mathrm{C}$ at the Research Center of the College of Pharmacy of King Saud University, Arabia Riyadh, Saudi Arabia. Chemical shifts are expressed in $\delta$-values (ppm) relative to TMS as an internal standard. Mass spectra were measured on an Agilent Triple Quadrupole 6410 QQQ LC/MS with an ESI (electrospray ionization) source (Santa Clara, CA, USA). The X-ray diffraction measurements of the title compound were performed using a Bruker SMART APEXII CCD diffractometer (Ettlingen, Germany). Crystallographic data have been deposited with the Cambridge Crystallographic Data Centre (supplementary publication number CCDC-933941) (Cambridge, UK).

\subsection{Synthesis}

Few drops of glacial acetic acid were added to a stirred solution of $N$-phenylhydrazinecarboxamide [12] (1.51 g, $10 \mathrm{mmol})$ and 3-(1H-imidazol-1-yl)-1-phenylpropan-1-one [13] (2.00 g, $10 \mathrm{mmol})$ in ethanol $(15 \mathrm{~mL})$. The resulting solution was stirred at room temperature for $18 \mathrm{~h}$. The reaction blend was evaporated under a vacuum, and the residue was crystallized from ethanol to yield $2.16 \mathrm{~g}(65 \%)$ of the title compound 2 as colorless crystals; m.p. 448-450 K. ${ }^{1} \mathrm{H}$ NMR (DMSO-d6): $\delta: 3.33$ (t, $J=7.6 \mathrm{~Hz}$, $\left.2 \mathrm{H},-\mathrm{CH}_{2}-\mathrm{CH}_{2}-\mathrm{N}\right), 4.13\left(\mathrm{t}, J=7.6 \mathrm{~Hz}, 2 \mathrm{H},-\mathrm{CH}_{2}-\mathrm{CH}_{2}-\mathrm{N}\right), 6.87(\mathrm{~s}, 1 \mathrm{H},-\mathrm{N}-\mathrm{CH}=\mathrm{CH}-\mathrm{N}=)$, $7.05(\mathrm{t}, J=7.35 \mathrm{~Hz}, 1 \mathrm{H}, \mathrm{Ar}-\mathrm{H}), 7.29(\mathrm{~s}, 1 \mathrm{H},-\mathrm{N}-\mathrm{CH}=\mathrm{CH}-\mathrm{N}=), 7.32$ (t, $J=8.0 \mathrm{~Hz}, 2 \mathrm{H}, \mathrm{Ar}-\mathrm{H})$, 7.41-7.43 (m, 3H, -N-CH=N-, Ar-H), 7.65 (d, $J=8.3 \mathrm{~Hz}, 3 \mathrm{H}, \operatorname{Ar}-\mathrm{H}), 7.85-7.86(\mathrm{~m}, 2 \mathrm{H}, \operatorname{Ar}-\mathrm{H})$, $8.88(\mathrm{~s}, \quad 1 \mathrm{H}, \mathrm{NH}), 10.27(\mathrm{~s}, 1 \mathrm{H}, \mathrm{NH}) ;{ }^{13} \mathrm{C}$ NMR (DMSO-d6): $\delta: 28.3 \quad\left(-\mathrm{CH}_{2}-\mathrm{CH}_{2}-\mathrm{N}\right)$, $42.1 \quad\left(-\mathrm{CH}_{2}-\mathrm{CH}_{2}-\mathrm{N}\right), \quad 119.4 \quad(-\mathrm{N}-\mathrm{CH}=\mathrm{CH}-\mathrm{N}=), \quad 119.9, \quad 122.6, \quad 126.4, \quad 128.3, \quad 128.4, \quad 128.5$, $128.9(-\mathrm{N}-\mathrm{CH}=\mathrm{CH}-\mathrm{N}=, \mathrm{Ar}-\mathrm{CH}), 136.8,137.3(\mathrm{Ar}-\mathrm{C}), 138.9(-\mathrm{N}-\mathrm{CH}=\mathrm{N}-), 145.1,153.6(\mathrm{C}=\mathrm{O}$, $\mathrm{C}=\mathrm{N}) ; \mathrm{MS} m / z(\mathrm{ESI}): 334.2[\mathrm{M}+1]^{+}[14]$.

\subsection{Quantum Chemical Calculations}

The structure of (2E)-HIPC was first optimized using the AM1 method and then refined with optimization by DFT/B3LYP and ab initio HF methods at the $6-311++\mathrm{G}(\mathrm{d}, \mathrm{p})$ level as implemented in the Gaussian 09 software [15]. The X-ray diffraction structure was used as the origin for the initial geometric optimization of the title compound. The vibrational frequencies at the HF and B3LYP levels 
of theory were evaluated for the optimized structures by assuming $C_{1}$ point group symmetry. The B3LYP and HF methods provide good predictions of the structural parameters and binding energies of (2E)-HIPC. No negative frequencies were obtained during the optimization. To improve the agreement of the computed values with the experimental data, a spectral uniform scaling factor was used to balance the systematic errors caused by basis set incompleteness, neglect of electron correlation and vibrational anharmonicity. Therefore, the vibrational wavenumbers computed at the HF level were scaled by 0.905 [16], and the wavenumbers computed using B3LYP were scaled by 0.958 for wavenumbers greater than $1700 \mathrm{~cm}^{-1}$ and by 0.983 for wavenumbers less than $1700 \mathrm{~cm}^{-1}[17,18]$. With a few exceptions, the differences from the experimental values were less than $10 \mathrm{~cm}^{-1}$ after rescaling using these scaling factors. The Gauss viewing program [19] was used for visualization and verification of the assigned normal modes.

The variations in the thermodynamic functional parameters (i.e., heat capacity, entropy, and enthalpy) were examined from 100 to $700 \mathrm{~K}$ using the computed wavenumbers of the title molecule. The electronic absorption spectra for the optimized molecule were calculated with TD-DFT at the B3LYP/6-311++G(d,p) level. To analyze the reactive sites of the title compound, the molecular electrostatic potential were computed using the HF and B3LYP methods in the gas phase. DMSO and acetonitrile solvents were used in the DFT/B3LYP/IEFPCM calculations to improve the prediction of the NMR values and achieve good accuracy. The chemical shifts were calculated and analyzed.

\section{Results and Discussion}

\subsection{Synthesis}

The title compound $\mathbf{2}$ was prepared in a three-step reaction sequence as depicted in Scheme 1.

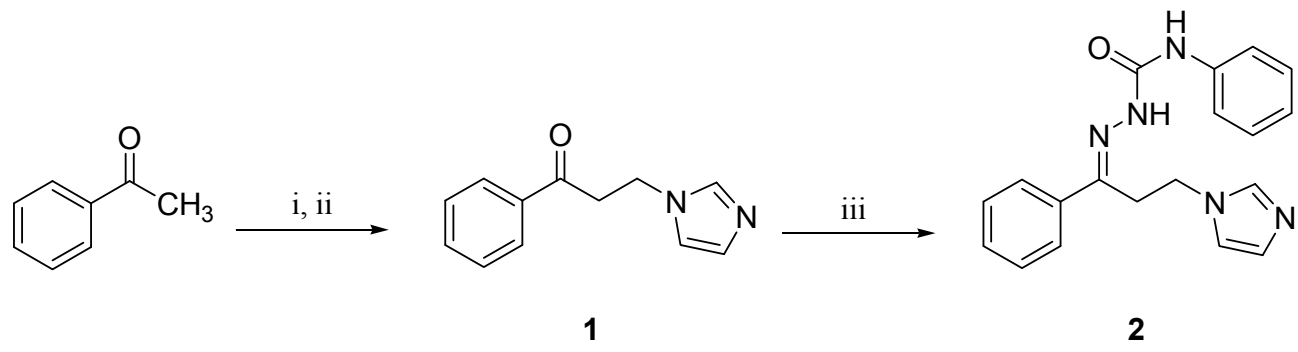

Scheme 1. Synthetic pathway for the target compound 2.

Reagents and conditions: (i) $\mathrm{HN}\left(\mathrm{CH}_{3}\right)_{2} \cdot \mathrm{HCl},\left(\mathrm{CH}_{2} \mathrm{O}\right)_{n}$, conc. $\mathrm{HCl}$, ethanol, reflux, $2 \mathrm{~h}$; (ii) imidazole, water, reflux, $5 \mathrm{~h}$; (iii) $\mathrm{N}$-phenylhydrazinecarboxamide, drops of acetic acid, ethanol, rt, $18 \mathrm{~h}$.

\subsection{X-ray Data Collection and Structure Description}

The crystal structure of $(2 E)$-HIPC contains one molecule in its asymmetric unit cell. The stereochemistry of the title compound $\left(\mathrm{C}_{19} \mathrm{H}_{19} \mathrm{~N}_{5} \mathrm{O}\right)$ about the imine bond was assigned as the (E)-configuration. In the urea moiety, the $\mathrm{N}-\mathrm{H}$ entities are trans to each other. The title compound crystallizes in the $P 21 / c$ monoclinic space group with $a=5.8093$ (2) $\AA$, $b=20.5575$ (6) $\AA$, $c=14.0355$ 
(5) $\AA$, $\alpha=90.00^{\circ}, \beta=97.365^{\circ}(2), \gamma=90.00^{\circ}, V=1662.36$ (10) $\AA^{3}$, and $Z=4$. The molecules are packed in the crystal structure by weak intermolecular hydrogen-bond interactions [14].

\subsection{Potential Energy Surface Scan Grid}

A potential energy surface scan was used to determine the optimized molecular structure of the (2E)-HIPC molecule in its equilibrium state and to determine the most stable structure at the global minimum of the potential energy surface. The energy surface scan grid for the title molecule was performed using the AM1 method, and the N16-C17-N18-C20 and C9-C8-C7-C5 dihedral angles were rotated for various geometries. The rotation angles of the two benzene rings with respect to the imidazole ring were computed by varying the dihedral angles. A potential energy scan of the (2E)-HIPC molecular geometry was performed by freezing the N16-C17-N18-C20 (SCAN1) and C9-C8-C7-C5 (SCAN2) dihedral angles and varying the dihedral angles values in 18 steps of $20^{\circ}$ from $-179^{\circ}$ to $179^{\circ}$ and from $0^{\circ}$ to $180^{\circ}$ for N16-C17-N18-C20 and C9-C8-C7-C5, respectively. A 3D view of the (2E)-HIPC rotational conformer is shown in Figure 1. This scan revealed that the optimized molecular geometries at 170 out of 361 with N16-C17-N18-C20 and C9-C8-C7-C5 dihedral angles of $-19.42^{\circ}$ and $440.713^{\circ}$, respectively, were the ground state conformations. The potential energy surface (PES) scan grid and the calculated optimized conformers were determined in the gas phase. The PES scan of the dihedral angle rotations resulted in 361 conformers. Two rotational global minimum energy conformers were identified for the title compound. Figure 1 illustrates the various levels of energies using colors where dark blue indicates the global minimum, light blue indicates a local minimum, red indicates a local maximum, and dark red indicates a global maximum.
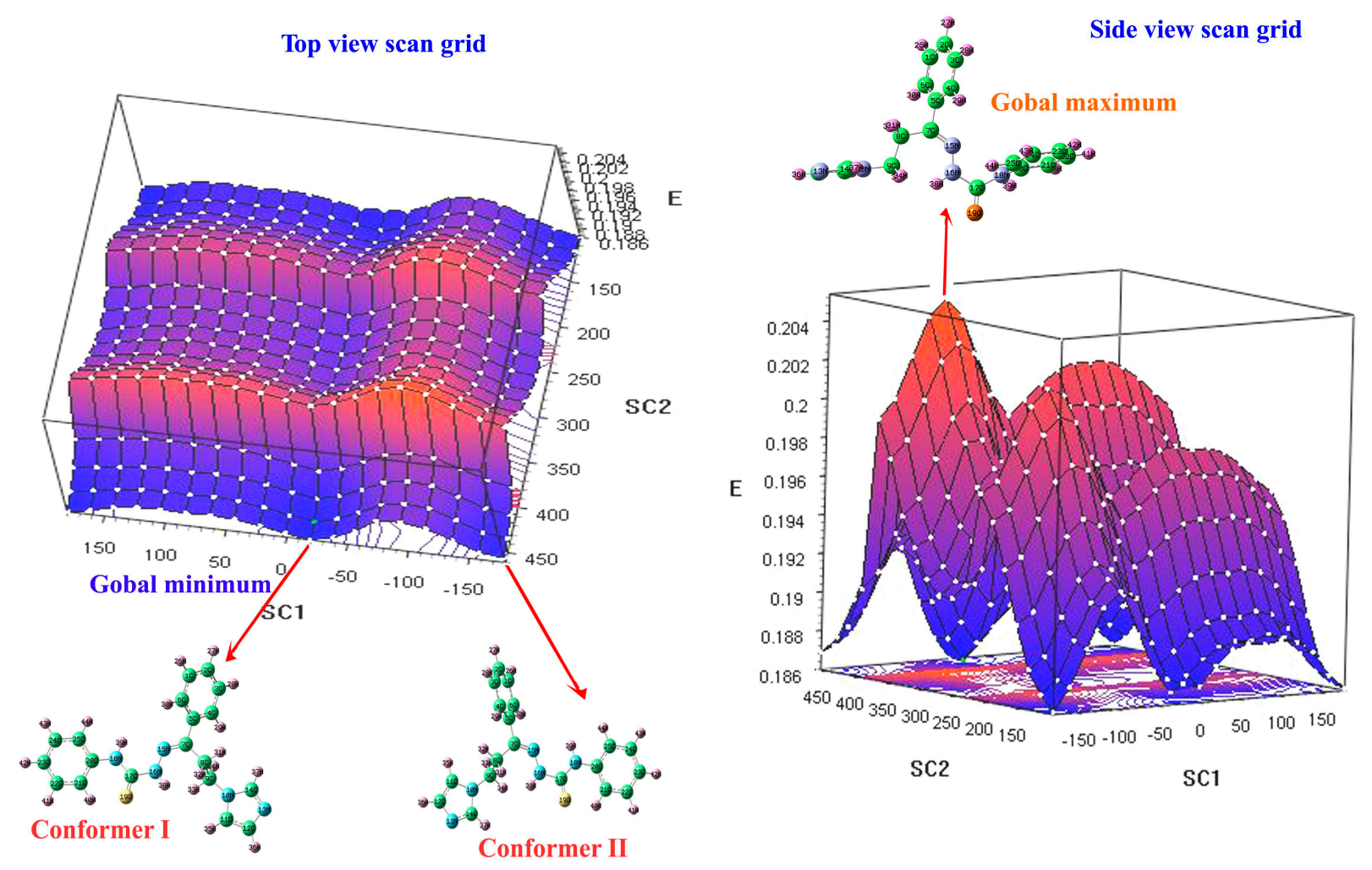

Figure 1. Potential energy surface grid of (2E)-HIPC. 
Rotational conformers I and II, which are shown in Figure 2, were optimized with the AM1 and B3LYP methods in the gas phase, DMSO, and acetonitrile. The global minimum energies and dipole moments for the conformers are presented in Table S1. Conformer I exhibited the lowest global minimum energies of 0.1695246 and -1084.70550 Hartree in DMSO solution using AM1 and B3LYP, respectively, compared with the obtained values in the gas phase and in acetonitrile. This result was confirmed by the computed dipole moment values in DMSO, which were 7.1931 and 7.4136 Debye using the AM1 and B3LYP methods, respectively. Therefore, conformer I was computed to have the minimum global energy, and this optimized molecular structure was used for further analysis.

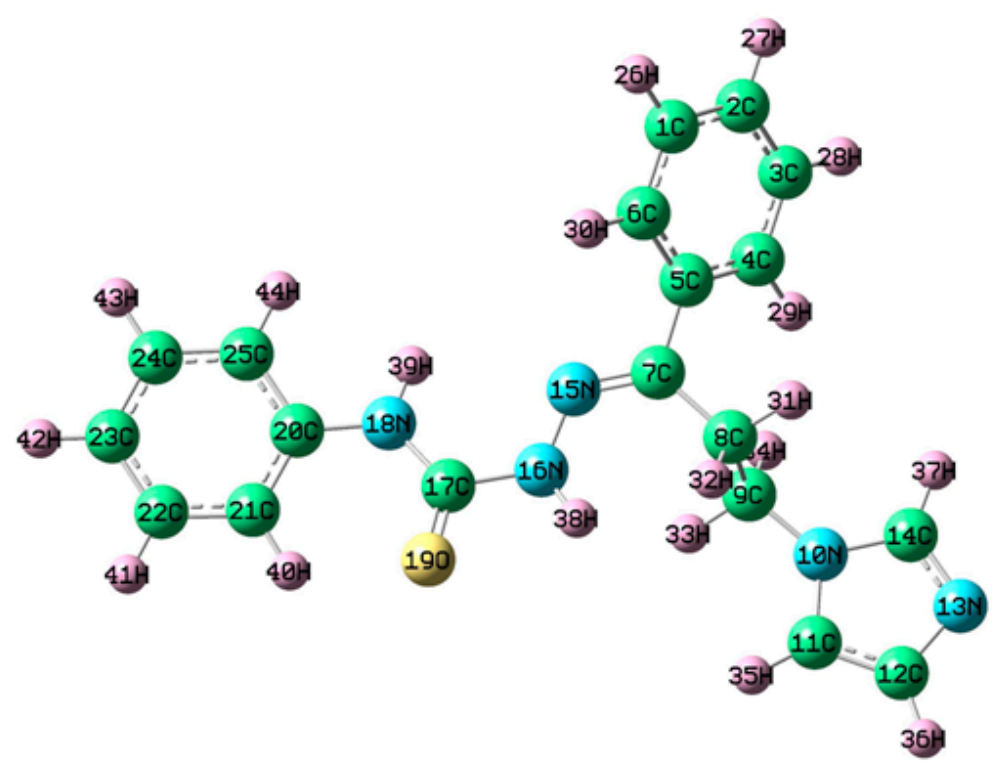

(A)

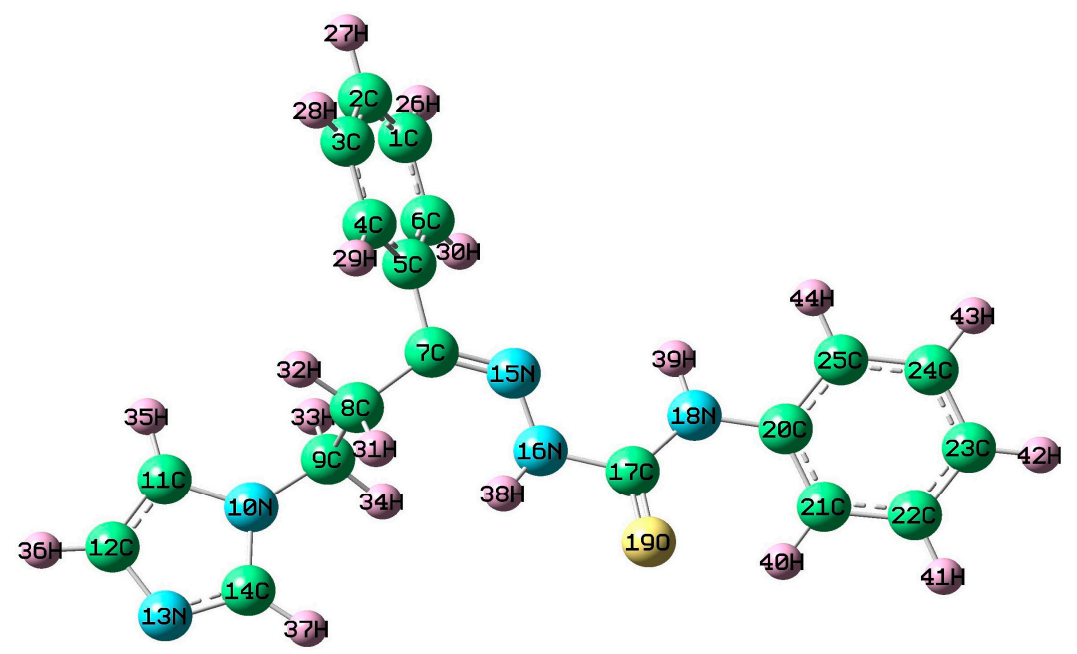

(B)

Figure 2. Rotational conformers of (2E)-HIPC. (A) Conformer I by rotation of scan $1=-71.425^{\circ}$ and scan $2=0^{\circ}$ or $360^{\circ}$. Energy (B3LYP) $=1084.7055$ hartree; (B) Conformer II by rotation of $\operatorname{scan} 1=-71.574^{\circ}$ and scan $2=0^{\circ}$ or $360^{\circ}$. Energy $(B 3 L Y P)=1084.6857$ hartree. 


\subsection{Geometry of the Title Molecule}

The optimized molecular structure of (2E)-HIPC with labeled atoms is shown in Figure 3. Selected optimized theoretical parameters in the gas phase and X-ray diffraction geometrical parameters of (2E)-HIPC are listed in Table S2. The optimized bond lengths of the $\mathrm{C}-\mathrm{C}$ bond in the phenyl ring of (2E)-HIPC fall in the range of 1.390-1.409 $\AA$ and $1.380-1.391 \AA$ in the B3LYP and HF methods, respectively. The observed XRD data for these bond lengths in (2E)-HIPC fall in the range from 1.368 to $1.393 \AA$, which are in good agreement with the values obtained using the HF method. The mean aromatic ring $\mathrm{C}-\mathrm{C}$ bond distance is $1.385 \AA$ by the $\mathrm{HF}$ method, which is consistent with the experimental value $(1.382 \AA)$. The optimized $\mathrm{C}-\mathrm{C}$ bond length in the imidazole ring of (2E)-HIPC is $1.353 \AA$ using the HF method, which is slightly longer than the observed XRD value $(1.350 \AA)$.

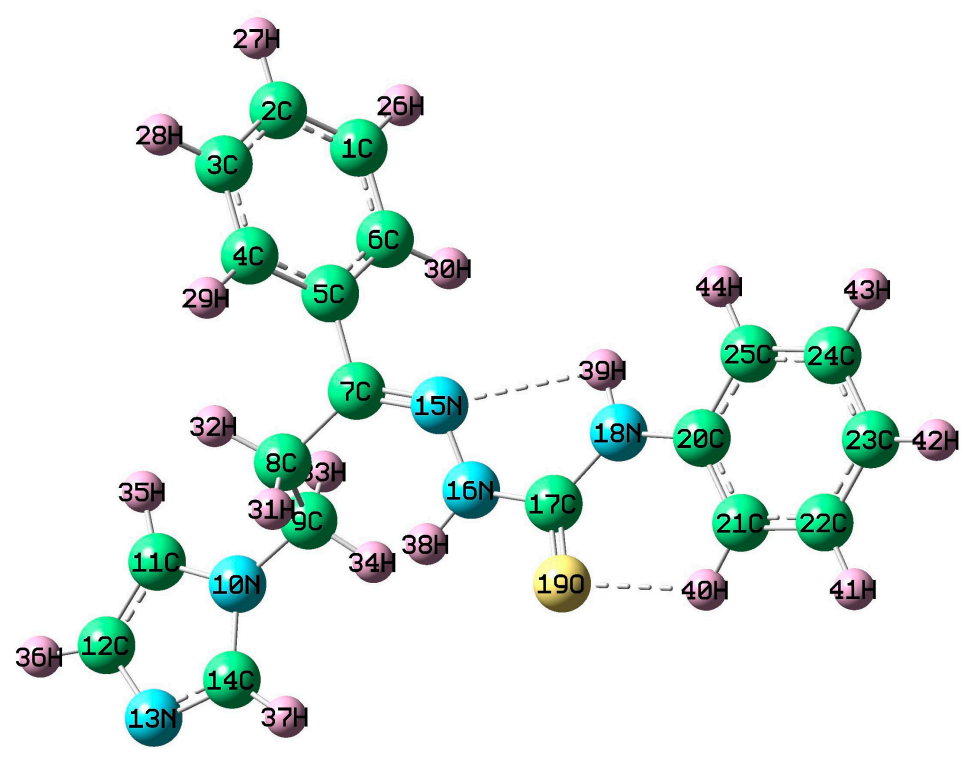

Figure 3. Optimized molecular structure of (2E)-HIPC.

The optimized bond length for the $\mathrm{C}=\mathrm{O}$ bond in the title compound is $1.221 \AA$ by the HF method, which is in a good agreement with the experimental value (1.227 $\AA$ ). It is interesting that the calculated N15-N16 bond length in the side chain of the title molecule is almost the same as the observed XRD value $(1.384 \AA)$. Based on the above comparisons, although there are some differences between our values and the literature data, the optimized geometric parameters can reproduce the literature values well and are the basis for subsequent discussion. The theoretical optimized $\mathrm{C}-\mathrm{H}$ bond lengths show large deviation from the experimental values, which may originate from the low scattering factors of hydrogen atoms in the XRD. The $\mathrm{C}-\mathrm{H}$ bond lengths determined using the HF method lead to geometric parameters that are much closer to the experimental data. The ring $\mathrm{C}-\mathrm{N}$ bond distances are in the range of 1.353 to $1.412 \AA$ using both the HF and B3LYP methods, while the observed XRD values are in the range of 1.347 to $1.418 \AA$. The longest bond length was found in $\mathrm{C} 20-\mathrm{N} 18$ due to the close $\mathrm{C}=\mathrm{O}$ group. The influence of different groups in the title compound on the bond length and dihedral angle parameters seems to be negligibly small. The mean angle deviation of the phenyl ring carbon atoms $\mathrm{C}-\mathrm{C}-\mathrm{C}$ was found to be greater by $0.2^{\circ}$ in the HF method and by $0.1^{\circ}$ in the B3LYP 
method than the corresponding XRD values. A large deviation was observed between theoretical and experimental XRD values in the bond angles of H38-N16-N15 and H35-C11-C12. The hydrogen bonding geometrical parameters [14] are presented in Table S3. The $\mathrm{N}-\mathrm{H} \cdots \mathrm{N}$ and $\mathrm{C}-\mathrm{H} \cdots \mathrm{O}$ bonds are identified as the $\mathrm{NH}$ and $\mathrm{CO}$ groups of (2E)-HIPC. These bonds are overestimated compared with the XRD values, whereas the $\mathrm{H} \cdots \mathrm{N}$ and $\mathrm{H} \cdots \mathrm{O}$ bonds are best fit with the HF and B3LYP values. Additionally, most of the intramolecular bond angles are in good agreement with the experimental values.

\subsection{Frontier Molecular Orbitals (FMOs) and Ultraviolet Spectral Analysis}

The excitation energies obtained using the TD-DFT/B3LYP method were computed for five excited electronic states. To enable a more relevant comparison between the theoretical and experimental data, the calculated transition energies were uniformly blue shifted such that the calculated and measured energies of the most intense transitions matched. The UV calculations were performed for a single molecule in the gas phase, DMSO, and acetonitrile without interactions with the environment, and the computed results were directly compared to the measured UV data for (2E)-HIPC in acetonitrile solution.
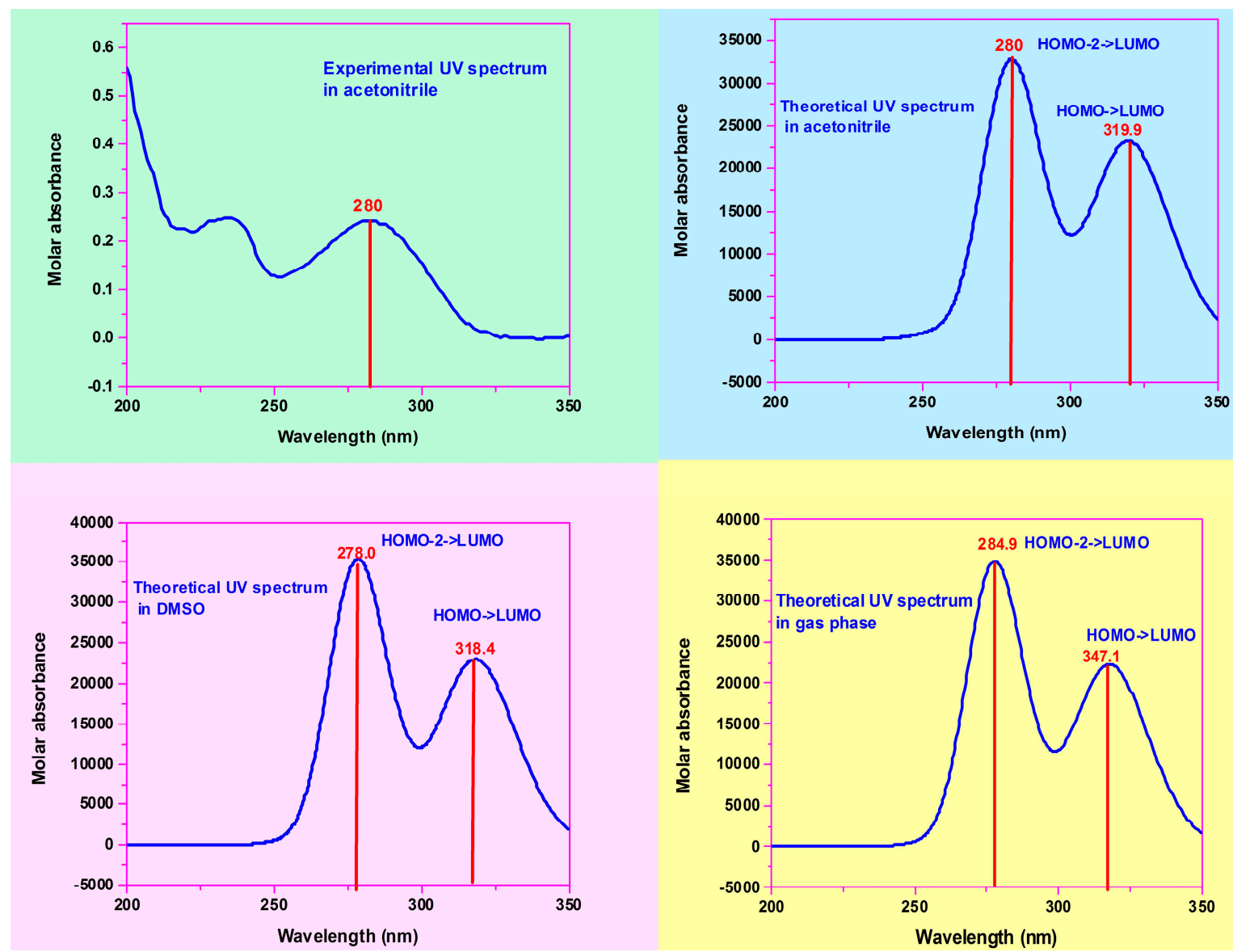

Figure 4. Theoretical (B3LYP) and experimental UV-Vis spectra of (2E)-HIPC.

The major energy contribution was approximately 0.98 in HOMO to LUMO for all three UV analyses. The 100-400 $\mathrm{nm}$ wavelength regions of the theoretical and experimental UV spectra of (2E)-HIPC are illustrated in Figure 4. The observed electronic absorption wavelengths at 250-320 nm were assigned to the $\pi$-to- $\pi^{*}$ transitions. The computed electronic absorption wavelengths were 
calculated to be $347.13,304.34,283.91,274.33$, and $267.55 \mathrm{~nm}$ in the gas phase; $318.40,286.17$, 278.08, 262.57, and 252.13 $\mathrm{nm}$ in DMSO; and 319.90, 287.47, 279.77, 265.00, and $254.05 \mathrm{~nm}$ in acetonitrile. The corresponding dipole moment values were 6.6951, 8.4925, and 8.6364 Debye. Based on a comparison of the dipole moments of DMSO and acetonitrile, more electronic transitions occur in acetonitrile due to its value. It is worth mentioning that the experimental and calculated absorption wavelengths are in good agreement, as shown in Figure 4.

HOMO-LUMO or frontier molecular orbitals (FMOs) are an important measure of the nonlinear optical and electric properties, which can be obtained from quantum chemistry, UV-Vis, and NMR spectra [20]. The HOMO has the ability to donate an electron, and the LUMO, which acts as an electron acceptor, has the ability to receive an electron. GaussSum 2.2 software [21] was used to calculate the minor and major energy contributions to the HOMOs and LUMOs. The energy gap between the FMOs determines the kinetic stability, chemical reactivity, optical polarizability, and chemical hardness/softness of a molecule. Chemical hardness and softness can be used as an additive tool to describe the thermodynamic aspects of chemical reactivity. To assess the trends in the transition energies of (2E)-HIPC, we carried out calculations for (2E)-HIPC in acetonitrile, DMSO, and the gas phase. The energies of the FMOs for (2E)-HIPC (i.e., HOMO, HOMO-1, LUMO and LUMO +1) were calculated at the B3LYP/6-311++G(d,p) level, and the results are listed in Table S4. The values of the HOMO-LUMO energy gap were 4.3772, 4.3994, and 4.0621 eV for (2E)-HIPC in acetonitrile, DMSO, and the gas phase, respectively.

The energy gap of the FMOs explains the ultimate charge transfer and interactions of atoms within the molecule. This activity influences the biological functions of the molecule. Three-dimensional plots of the HOMO and LUMO orbitals were computed at the B3LYP/6-311++G(d,p) level. Positive charge is shown in violet, and negative charge is shown in green. Based on the results shown in Figure 5, although the HOMO was localized on one benzene ring, the LUMO was localized on a different benzene ring as well as on the chain linking the two rings.
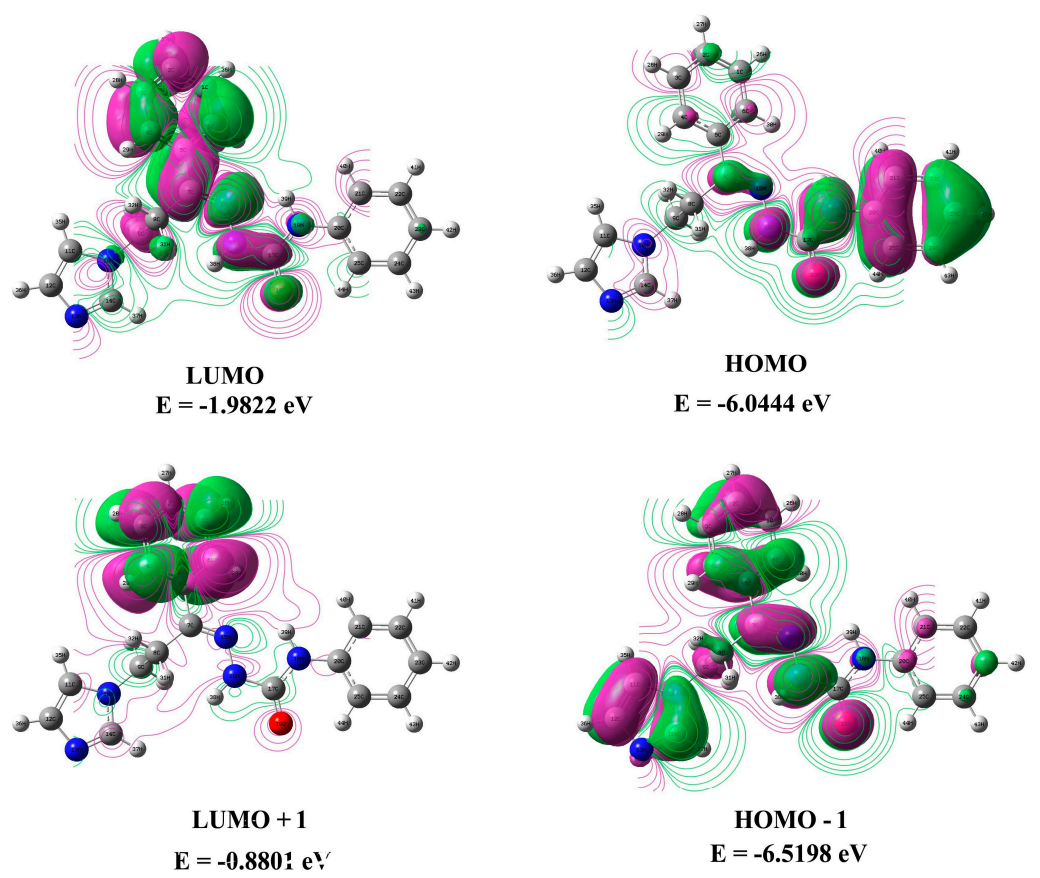

Figure 5. 3D plots of the HOMO and LUMO of (2E)-HIPC at the B3LYP level. 
The values of electronegativity, chemical hardness, softness, and electrophilicity index for (2E)-HIPC in acetonitrile were 3.9125, 2.1886, 1.0943 , and $5.2418 \mathrm{eV}$, respectively. These values are between the corresponding values for (2E)-HIPC in DMSO and in the gas phase. The lowest value of the dipole moment was calculated for the gas phase. The stronger intermolecular interactions in acetonitrile are due to the dipole moment value being larger than those in DMSO and the gas phase.

The electronic transitions and UV spectra of (2E)-HIPC were computed using the TD-DFT/IEFPCM approach at the B3LYP/6-311++G(d,p) level. The calculations were performed for $(2 E)$-HIPC in acetonitrile, DMSO, and the gas phase. The frontier orbital energies, absorption wavelengths $(\lambda)$, oscillator strengths $(f)$, and excitation energies (E) for (2E)-HIPC were computed in the gas phase, DMSO, and acetonitrile; the data are presented in Table S5. TD-DFT calculations for (2E)-HIPC predicted an intense electronic transition at $279.7 \mathrm{~nm}(f=0.4339)$ in acetonitrile, $278.0 \mathrm{~nm}(f=0.4700)$ in DMSO, and $284.9 \mathrm{~nm}(f=0.5114)$ in the gas phase. The observed differences are due to shifting of the bands in both DMSO and acetonitrile due to their permittivities. The results are better represented in graphical form, as shown in Figure 4. Experimentally, absorption peaks of (2E)-HIPC in acetonitrile were observed at 283.1, 234.9, and $199.4 \mathrm{~nm}$. The observed values are shifted downfield compared with the corresponding computed values. The major energy contributions were computed.

\subsection{Electrostatic Potentials, Total Electron Densities, and Molecular Electrostatic Potentials}

The molecular electrostatic potentials (MEPs) of the title compound were calculated using the B3LYP and HF methods in the gas phase, as shown in Figure 6. The MEP maps of (2E)-HIPC indicate that the regions of negative electrostatic potential lie outside of the compound and near the oxygen atom. For the imidazole ring of $(2 E)$-HIPC, the negative electrostatic potential lies outside the ring.

Therefore, no favorable location exists for the formation of a normal cation above the ring. The molecular electrostatic potential (red color) was located on the $\mathrm{N}$ and $\mathrm{O}$ atoms belonging to the imidazole ring and $\mathrm{C}=\mathrm{O}$ group, respectively. Less negative values were observed on the $\mathrm{N}-\mathrm{H}$ groups (blue color). Both regions should be different because they are the principal acceptor and donor sites of the $\mathrm{H}$ bonds. In the vicinity of the nitrogen and oxygen atoms, the charge magnitude varies from -0.008 to -0.02 . In the benzene ring, the charges vary from 0.008 to 0.8 from the inner to the outer contour. The electrostatic potential of different atoms on the surface is represented by different colors. The value of the electrostatic potential increased from red (more negative) to blue (more positive). The coloring of these maps represents a range of -0.06023 a.u. (deepest red) to 0.06023 a.u. (deepest blue) at the B3LYP/6-311++G(d,p) level and -0.06321 a.u. to 0.06321 a.u. at the HF/6-311++G(d,p) level. The atomic sites colored in the MEP map indicate the strongest attraction in blue and the strongest repulsion in red. The electrostatic potential of $\mathrm{C} 17$ is more positive $(0.718286)$ due to the high electronegativity of the neighboring O19 atom. N18 is more negative $(-0.638291)$ due to the nearby oxygen and intramolecular bonding of H39 with N15. All of the hydrogen atoms have positive potentials. $\mathrm{C} 7$ and $\mathrm{C} 8$ have positive potentials, and $\mathrm{C} 9$ has a negative potential in the side chain carbon atoms. All carbons in the rings have negative electrostatic potentials except for $\mathrm{C} 14$ due to its bonding with two nitrogen atoms. 


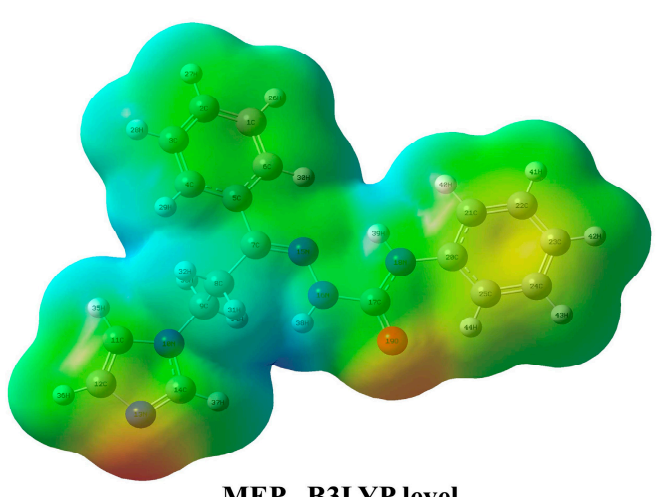

MEP B3LYP level

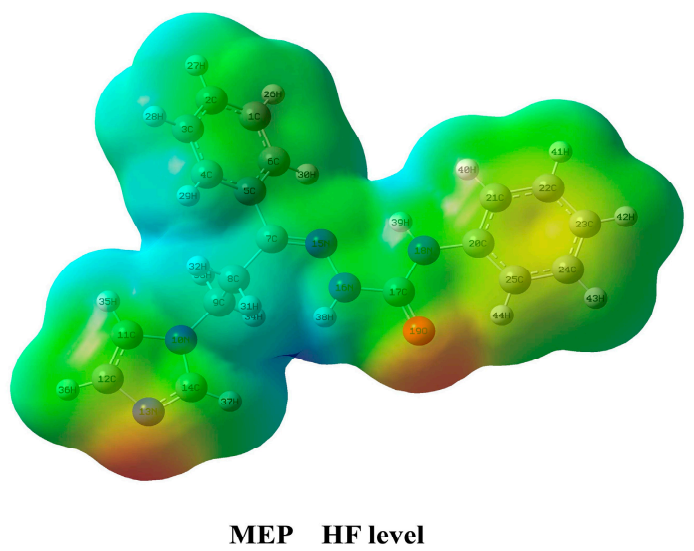

$-0.07092 \mathrm{e}$

+0.07092 e -0.0776 e

$+0.0776 \mathrm{e}$

(A)

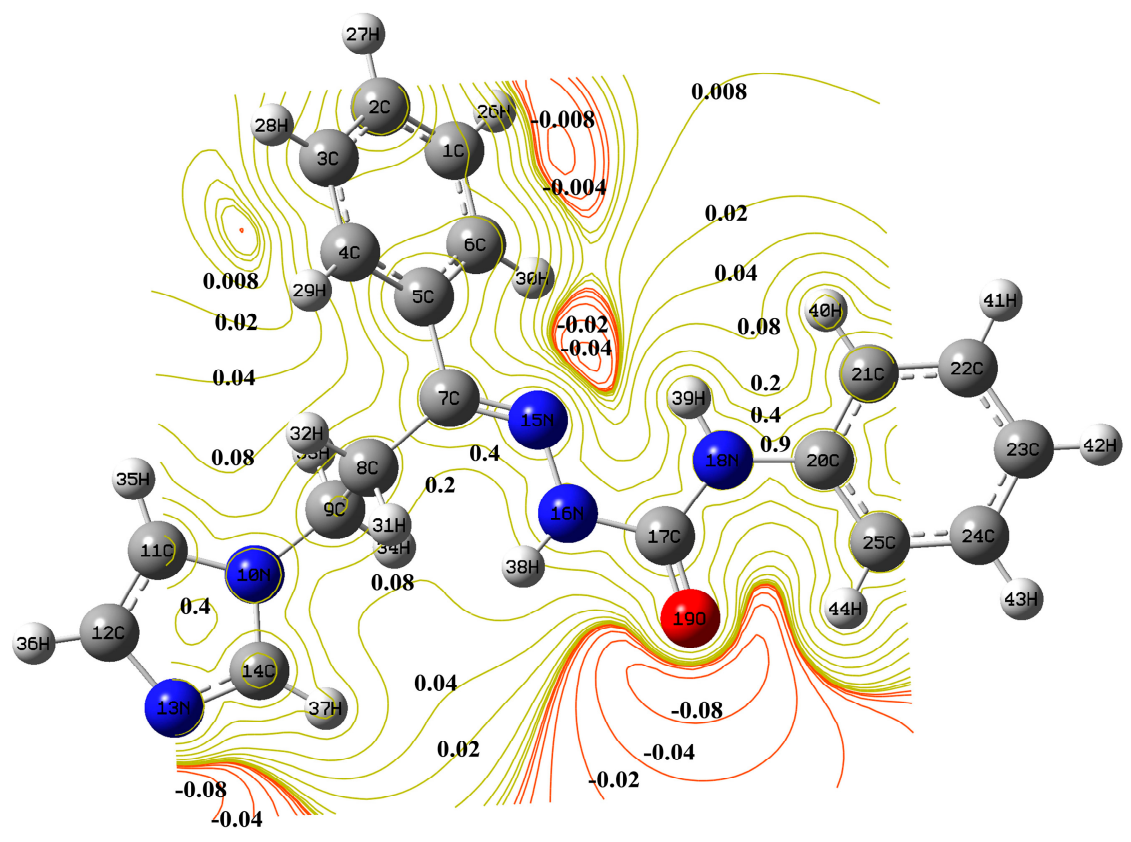

(B)

Figure 6. A representative illustration of the molecular electrostatic potentials (MEPs) (A) and contour map of (2E)-HIPC (B).

\subsection{Infrared and Raman Spectral Analysis}

In addition to three translational and three rotational degrees of freedom, the maximum number of potentially active normal modes of vibrations of a nonlinear molecule that contains $\mathrm{N}$ atoms is equal to (3N-6). All of the normal modes of vibration are both Raman and infrared active. The vibrational wavenumbers were calculated using the DFT/B3LYP method and the results, which were compared with the experimental values, are presented in Table S6. This comparison indicated that the calculated vibrational frequencies were overestimated due to the anharmonicity in the real system. The assigned vibrational modes of the experimental bands are based on normal mode analysis and comparison with the theoretically scaled wavenumbers obtained using the B3LYP method. The experimental and simulated FT-IR and FT-Raman spectra of (2E)-HIPC are shown in Figures 7 and 8, respectively. 


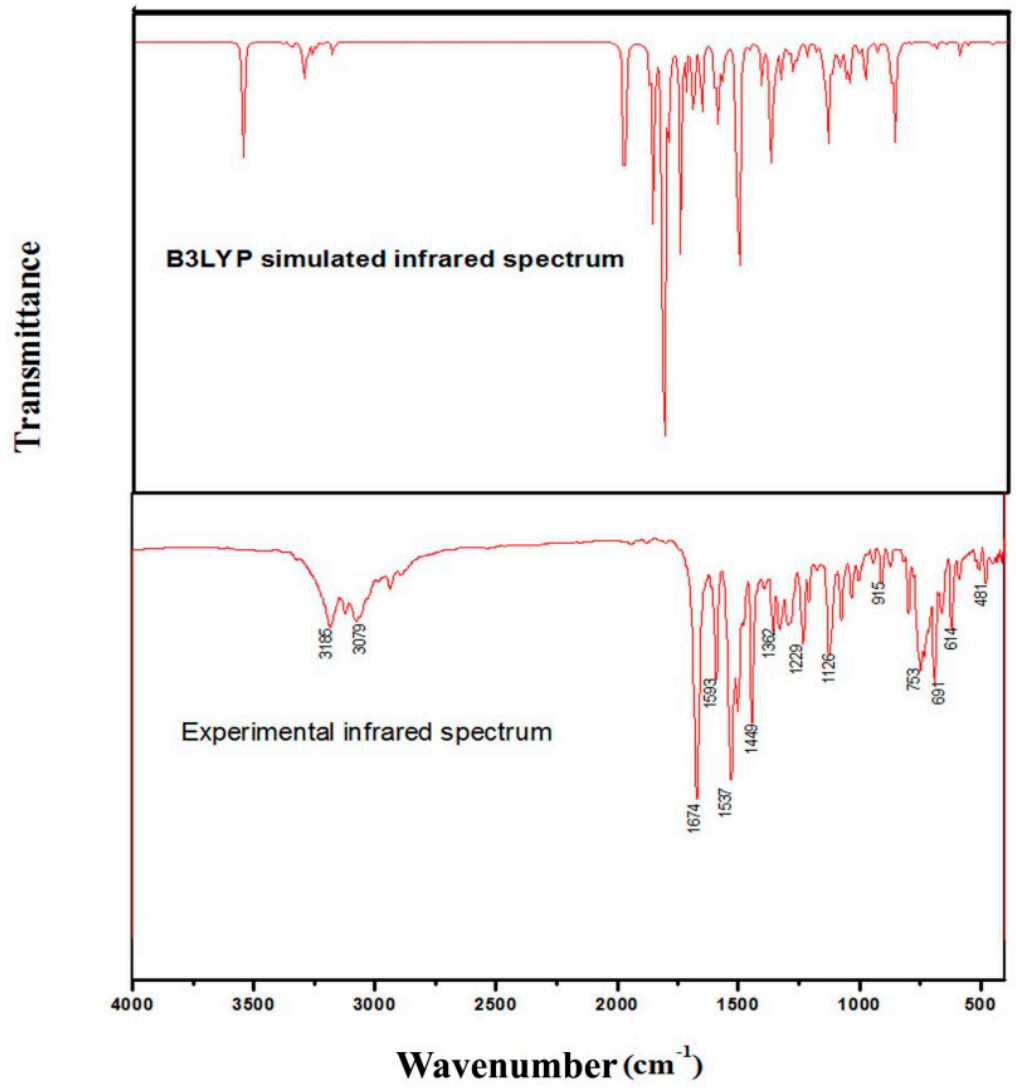

Figure 7. Theoretical (B3LYP) and experimental infrared spectra of (2E)-HIPC.

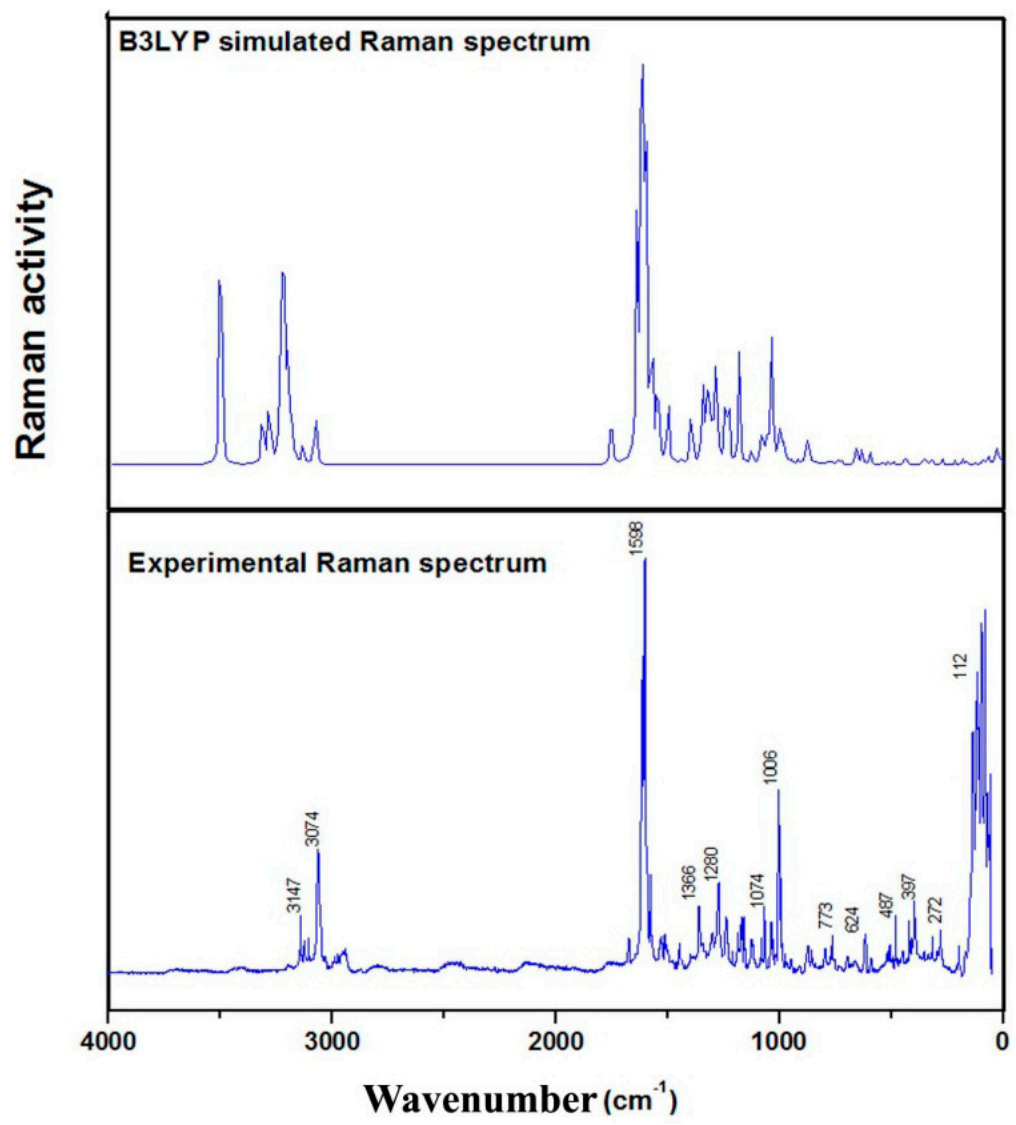

Figure 8. Theoretical (B3LYP) and experimental Raman spectra of (2E)-HIPC. 


\subsection{1. $\mathrm{C}-\mathrm{H}$ Vibrations}

The aromatic rings exhibit $\mathrm{C}-\mathrm{H}$ stretching as well as in-plane and out-of-plane bending vibrations. Aromatic compounds commonly exhibit multiple weak bands in the $3100-3000 \mathrm{~cm}^{-1}$ region [22] due to ring $\mathrm{C}-\mathrm{H}$ stretching vibrations. These vibrations are not strongly affected by the nature of the substituents $[23,24]$. All of the $\mathrm{C}-\mathrm{H}$ stretching vibration modes exhibit very weak intensities. In the current study, (2E)-HIPC exhibits $10 \mathrm{C}-\mathrm{H}$ stretching vibrations. Among the four expected $\mathrm{C}-\mathrm{H}$ stretching vibrations, three were observed at 3048,2930 , and $2908 \mathrm{~cm}^{-1}$ in the FT-IR spectra, and the same types of vibrations were observed at 3023, 2980, 2930, and $2880 \mathrm{~cm}^{-1}$ in the FT-Raman spectra. These vibrations are shifted downfield due to the imidazole moiety and the side-chain substitutions. All of the bands were observed as weak vibrations.

The vibrational modes due to $\mathrm{C}-\mathrm{H}$ in-plane bending vibrations were observed in the $1000-1300 \mathrm{~cm}^{-1}$ region [25]. For the title compound, the $\mathrm{C}-\mathrm{H}$ in-plane bending vibrations were observed at 1198, 1180, 1165 , and $1152 \mathrm{~cm}^{-1}$. The wavenumbers obtained using the B3LYP/6-311++G(d,p) level of theory and subsequently rescaled were in good agreement with the experimentally observed data. The $\mathrm{C}-\mathrm{H}$ out-of-plane bending vibrations appear in the $1000-700 \mathrm{~cm}^{-1}$ region [26]. The vibrations identified at $740,730,713$, and $700 \mathrm{~cm}^{-1}$ were attributed to $\mathrm{C}-\mathrm{H}$ out-of-plane bending for $(2 E)$-HIPC.

\subsubsection{Skeletal Vibrations}

\section{C-C Vibrations}

Aromatic $\mathrm{C}=\mathrm{C}$ stretching vibrations appear in the $1430-1625 \mathrm{~cm}^{-1}$ region, and the ring stretching vibrations for $\mathrm{C}-\mathrm{C}$ are expected to appear in the $1300-1000 \mathrm{~cm}^{-1}$ region [27-29]. The ring vibrations can vary due to different substitutions. In our investigation, the band at $1425 \mathrm{~cm}^{-1}$ in the FT-IR spectrum and the bands at $1579,1540,1516,1495$, and $1406 \mathrm{~cm}^{-1}$ in the Raman spectrum were assigned to $\mathrm{C}=\mathrm{C}$ stretching vibrations. The band at $1301 \mathrm{~cm}^{-1}$ was assigned to a $\mathrm{C}-\mathrm{C}$ vibration. The $\mathrm{C}-\mathrm{C}-\mathrm{C}$ dihedral in-plane and out-of-plane bending vibrations were observed at 996, 980, 965, 936, 910, and $761 \mathrm{~cm}^{-1}$ and $405,396,345,322,285$, and $160 \mathrm{~cm}^{-1}$ in the expected region, respectively. The theoretical values exhibited excellent agreement with the experimental ones. As anticipated, the in-plane deformations were observed at higher frequencies than the out-of-plane vibrations.

\section{Carbon-Oxygen Vibrations}

In the $\mathrm{C}=\mathrm{O}$ bond, the lone pair of electrons in the oxygen determine the nature of the carbonyl group. The $\mathrm{C}=\mathrm{O}$ bond functionality and the carbonyl stretching vibration have been previously studied by infrared spectroscopy [30]. This multiple bonded group is highly polar and therefore gives rise to an intense infrared absorption band. Carboxylic acids are identified by the $\mathrm{C}=\mathrm{O}$ vibration, which gives rise to a strong absorption between 1700 and $1800 \mathrm{~cm}^{-1}$. In general, the $\mathrm{C}=\mathrm{O}$ stretching modes of acids are more intense than those for ketonic stretching modes. The characteristic ketonic $\mathrm{C}=\mathrm{O}$ band in the current study appear at $1620 \mathrm{~cm}^{-1}$ in the FT-Raman spectrum, and this peak is very intense [31]. The $\pi-\pi$ bonding between the carbon and oxygen results in the formation of a double bond, and intermolecular hydrogen bonding reduces the wavenumbers of the $\mathrm{C}=\mathrm{O}$ stretching absorption to a 
greater degree than the presence of the molecular $\mathrm{H}$. This $\mathrm{C}=\mathrm{O}$ vibrational mode of the title molecule appears in the expected range, which indicated that it was not strongly affected by other vibrational modes. The computed $\mathrm{C}=\mathrm{O}$ frequency, which was calculated at the B3LYP/6-311G(d,p) level of theory, was $1622 \mathrm{~cm}^{-1}$, which strongly supports the assignment of the experimental data.

\section{$\mathrm{N}-\mathrm{H}$ Vibrations}

The $\mathrm{N}-\mathrm{H}$ stretching modes typically occur in the $3500-3300 \mathrm{~cm}^{-1}$ region. The asymmetric $-\mathrm{NH}$ stretching mode appears in the range from 3500 to $3420 \mathrm{~cm}^{-1}$, and the symmetric $-\mathrm{NH}$ stretching mode occurs in the $3420-3340 \mathrm{~cm}^{-1}$ region. In the current investigation, the title compound exhibited one N16-H38 asymmetric stretch at $3590 \mathrm{~cm}^{-1}$ and one N18-H39 symmetric stretch at $3433 \mathrm{~cm}^{-1}$, which are in agreement with the $\mathrm{B} 3 \mathrm{LYP} / 6-311 \mathrm{G}++(\mathrm{d}, \mathrm{p})$ calculated values. The $\mathrm{NH}_{2}$ in-plane deformation vibrations occur in the $1650-1580 \mathrm{~cm}^{-1}$ wavelength region of the spectrum. Therefore, a very strong band was observed in the FT-IR spectra of (2E)-HIPC at $1315 \mathrm{~cm}^{-1}$, which was assigned to the in-plane deformation mode of the $-\mathrm{NH}$ group. The $-\mathrm{NH}$ out-plane bending was observed at $655 \mathrm{~cm}^{-1}$ in the FT-IR spectrum.

\subsection{NMR Analysis}

NMR parameters are used to determine the chemical environment of the molecule. The isotopic shifts provide essential information for understanding the microscopic environment of the molecules. DFT calculations were used to assign and analyze the experimental NMR spectra. DFT calculations were performed for $(2 E)$-HIPC in different solvents to improve the accuracy of the predicted NMR values. The observed and simulated ${ }^{1} \mathrm{H}$ and ${ }^{13} \mathrm{C}$ NMR spectra of (2E)-HIPC are shown in Figure 9. The observed and theoretical values from the ${ }^{1} \mathrm{H}$ and ${ }^{13} \mathrm{C}$ NMR spectra of (2E)-HIPC are listed in Table S7. The chemical shifts were calculated for $(2 E)$-HIPC in DMSO and acetonitrile, and the results were compared with the experimental data for (2E)-HIPC in DMSO. In the ${ }^{1} \mathrm{H}$ NMR spectrum, the signal at $145.1 \mathrm{ppm}$ was due to the carbon atom (C17) attached to the oxygen atom. Similarly, the peaks located at 153.6 and $138.9 \mathrm{ppm}$ were due to carbon atoms in the side chain, C7 and C14, respectively, located between the two nitrogen atoms in the imidazole ring. The chemical shifts for carbon atoms C20 and $\mathrm{C} 5$ in the benzene rings increased due to the attachment of the side chains. Of these two carbon atoms, C20 was upshifted due to its attachment to a nitrogen atom. In addition, the computed values were higher than the observed values. The chemical shifts of ring carbon atoms C2, C4, C6, C24, C22, C1, and $\mathrm{C} 3$ were observed at $128 \mathrm{ppm}$. The chemical shifts of the first two carbons (i.e., $\mathrm{C} 2$ and $\mathrm{C} 4$ ) were estimated to be smaller than the calculated values. The more upfield-shifted carbon atoms in the benzene ring were $\mathrm{C} 21, \mathrm{C} 23$, and $\mathrm{C} 25$. The observed chemical shifts of the imidazole ring carbon atoms (i.e., $\mathrm{C} 11$ and $\mathrm{C} 12$ ) were 119.4 and 126.4 ppm, respectively.

The ${ }^{1} \mathrm{H}$ NMR spectrum of (2E)-HIPC contains five sets of peaks between 3.33 and $10.27 \mathrm{ppm}$. The ${ }^{1} \mathrm{H}$ NMR signal splitting was caused by spin-spin coupling between nearest nuclei. The two triplets obtained at 3.33 and $4.13 \mathrm{ppm}$ were due to the splitting of the signals of the side-chain hydrogen atoms and were assigned to the equivalent protons H31 and H32 and to the equivalent protons $\mathrm{H} 33$ and $\mathrm{H} 34$, respectively. The two triplets observed at 3.33 and $4.13 \mathrm{ppm}$ were due to the splitting of the signals of the side-chain hydrogen atoms. The ${ }^{1} \mathrm{H}$ NMR splitting from 6.87 to $7.43 \mathrm{ppm}$ 
was due to the signals from the hydrogen atoms (i.e., $\mathrm{H} 35, \mathrm{H} 36$, and H37) attached to the imidazole ring. The observed signal due to NH38 at 10.27 ppm exhibited a large chemical shift compared with the calculated values for (2E)-HIPC in DMSO and acetonitrile. The signal of the other NH39 exhibited an upfield chemical shift $(8.88 \mathrm{ppm})$ due to intramolecular hydrogen bonding with N15. This intramolecular hydrogen bonding was confirmed by comparison to the calculated values for (2E)-HIPC in both DMSO and acetonitrile. The root mean square deviations (RMSDs) for ${ }^{13} \mathrm{C}$ NMR are 4.499 and 3.794 in DMSO and acetonitrile, respectively. However, a small deviation was observed for ${ }^{1} \mathrm{H}$ NMR in both solvents. The calculated chemical shift values for both the ${ }^{1} \mathrm{H}$ and ${ }^{13} \mathrm{C}$ NMR spectra of (2E)-HIPC in DMSO exhibited good linear fits with the experimental values.
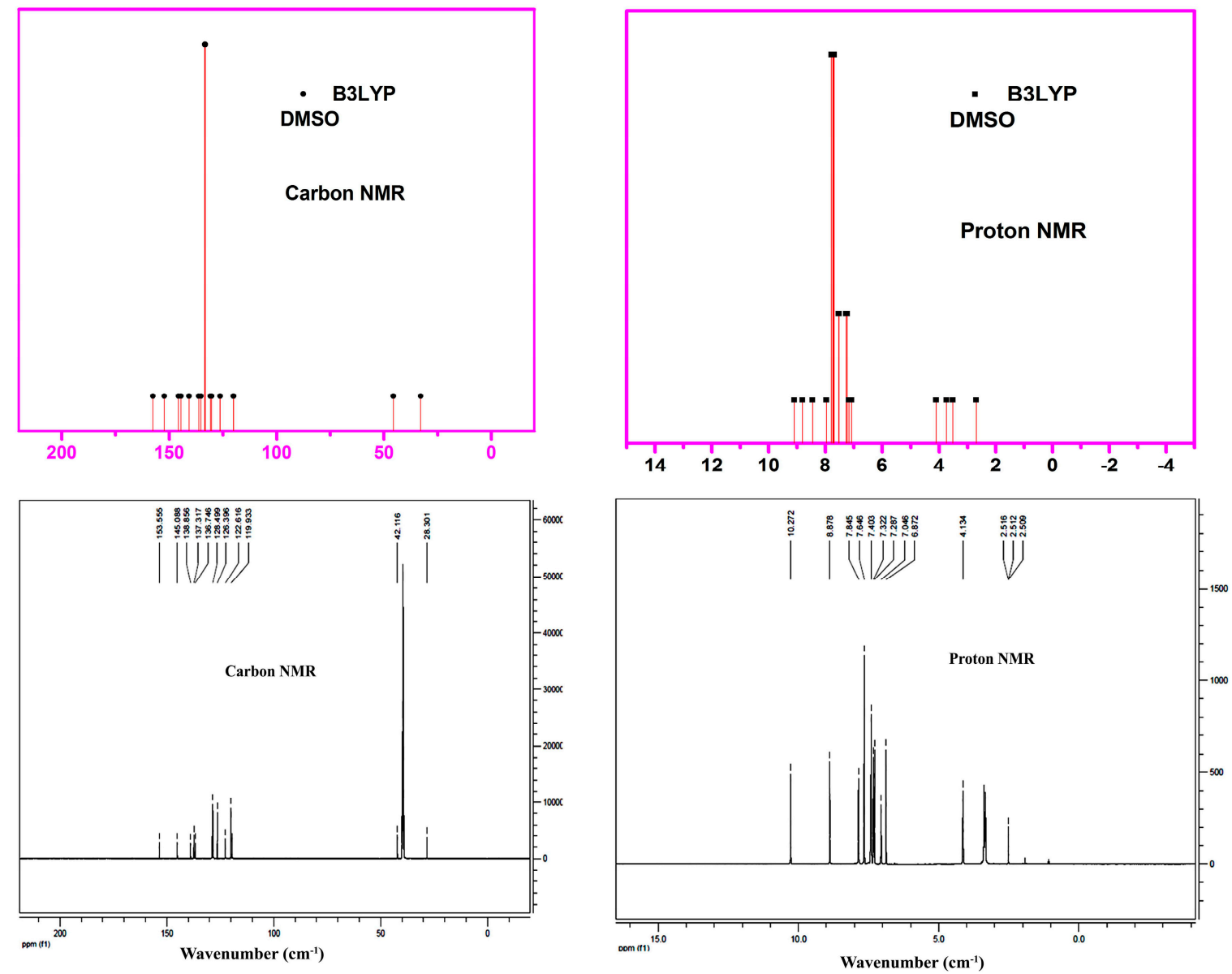

Figure 9. Theoretical and experimental ${ }^{13} \mathrm{C}$ and ${ }^{1} \mathrm{H}$ NMR of (2E)-HIPC.

\section{Conclusions}

A complete vibrational analysis of $(2 E)$-HIPC was performed using the HF and DFT-B3LYP methods with the $6-311 \mathrm{G}++(\mathrm{d}, \mathrm{p})$ basis sets. The stable rotational conformer of our molecule was identified via a potential energy surface grid scan using the AM1 and B3LYP methods. The global minimum energy and dipole moment were analyzed, and conformer I was used for further calculations. The standard statistical thermodynamic functions were obtained from the theoretical harmonic frequencies at the B3LYP and HF levels in the gas phase. The correlation equations between the statistical thermodynamic functions and temperature were also obtained. The thermodynamic 
functions fit well with regression values of 0.9999. The electronic transitions of the title compound were determined using TD-DFT calculations in acetonitrile, DMSO and the gas phase to simulate the electronic absorption spectrum of $(2 E)$-HIPC. The electronic transitions are more intense in acetonitrile than in DMSO. In the acetonitrile solvent, the observed values were shifted downfield compared with the computed values. The observed and simulated spectra had good agreement when using the DFT-B3LYP/6-311G++(d,p) method. The RMSD value was lower in acetonitrile than in DMSO for ${ }^{13} \mathrm{C}$ NMR, while for ${ }^{1} \mathrm{H}$ NMR, there was not much deviation in either solvent.

\section{Acknowledgments}

The authors would like to extend their sincere appreciation to the Deanship of Scientific Research at King Saud University for its funding of this research through the Research Group Project No. RGP-VPP-196.

\section{Author Contributions}

All authors discussed the contents of the manuscript and contributed to its preparation. Munusamy Govindarajan performed the computational work. Ali S. Abdelhameed carried out UV measurements. Abdulaziz A. Al-Saadi recorded FT-IR and FT-Raman spectra. Mohamed I. Attia synthesized and characterized the title molecule.

\section{Conflict of Interests}

The authors declare no conflict of interest.

\section{References}

1. Chang, B.S.; Lowenstein, D.H. Epilepsy. N. Engl. J. Med. 2003, 349, 1257-1266.

2. Meldrum, B.S.; Bruton, C.J. Epilepsy. In Greenfield's Neuropathology; Adams, J.H., Duchen, L.W., Eds.; Oxford University Press: New York, NY, USA, 1992; pp. 1246-1283.

3. Thiry, A.; Dogne, J.M.; Supuran, C.T.; Masereel, B. Carbonic anhydrase inhibitors as anticonvulsant agents. Curr. Top. Med. Chem. 2007, 7, 855-864.

4. Remi, J.; Hüttenbrenner, A.; Feddersen, B.; Noachtar, S. Carbamazepine but not pregabalin impairs eye control: A study on acute objective CNS side effects in healthy volunteers. Epilepsy Res. 2010, $88,145-150$.

5. Taylor, D.M.; Young, C.; Paton, C. Prior Antipsychotic Prescribing in Patients Currently Receiving Clozapine: A Case Note Review. J. Clin. Psychiatry 2003, 64, 30-34.

6. Kennedy, G.M.; Lhatoo, S.D. CNS adverse events associated with antiepileptic drugs. CNS Drugs 2008, 22, 739-760.

7. Penovich, P.E.; Willmore, L.J. Use of a new antiepileptic drug or an old one as first drug for treatment of absence epilepsy. Epilepsia 2009, 50, 37-41.

8. Barkmeier, D.T.; Loeb, J.A. An animal model to study the clinical significance of interictal spiking. Clin. EEG Neurosci. 2009, 40, 234-238. 
9. Graziani, G.; Cazzulani, P.; Luca, C. Denzimol, a new anticonvulsant drug. II. General pharmacological activities. Arzneimittelforschung 1983, 33, 1161-1168.

10. Dimmock, J.R.; Vashishtha, S.C.; Stables, J.P. Anticonvulsant properties of various acetylhydrazones, oxamoylhydrazones and semicarbazones derived from aromatic and unsaturated carbonyl compounds. Eur. J. Med. Chem. 2000, 35, 241-248.

11. Attia, M.I.; Aboul-Enein, M.N.; El-Azzouny, A.A.; Maklad, Y.A.; Ghabbour, H.A. Anticonvulsant Potential of Certain New (2E)-2-[1-aryl-3-(1H-imidazol-1-yl)propylidene]- $N$ (aryl/H)hydrazinecarboxamides. Sci. World J. 2014, 2014, 1-9.

12. Aboul-Enein, M.N.; El-Azzouny, A.A.; Attia, M.I.; Maklad, Y.A.; Amin, K.M.; Abdel-Rehim, M.; El-Behairy, M.F. Design and synthesis of novel stiripentol analogues as potential anticonvulsants. Eur. J. Med. Chem. 2012, 47, 360-369.

13. Aboul-Enein, M.N.; El-Azzouny, A.A.; Attia, M.I.; Saleh, O.A.; Kansoh, A.L. Synthesis and anti-candida potential of certain novel 1-[(3-substituted-3-phenyl)propyl]-1H-imidazoles. Arch. Pharm. Chem. Life Sci. 2011, 344, 794-801.

14. Attia, M.I.; Ghabbour, H.A.; El-Azzouny, A.A.; Al-Deeb, O.A.; Almutairi, M.S.; Fun, H.-K. Synthesis and single crystal X-ray structure of new (2E)-2-[3-(1H-imidazol-1-yl)-1phenylpropylidene]- $N$-phenylhydrazinecarboxamide. J. Chem. 2013, 2013, 1-5.

15. Frisch, M.J.; Trucks, G.W.; Schlegel, H.B.; Scuseria, G.E.; Robb, M.A.; Cheeseman, J.R.; Montgomery, J.A., Jr.; Vreven, T.; Kudin, K.N.; Burant, J.C.; et al. Gaussion 03 Program; Gaussian, Inc.: Wallingford, CT, USA, 2004.

16. Young, D.C. Computational Chemistry: A Practical Guide for Applying Techniques to Real World Problems (Electronic); John Wiley \& Sons Inc.: New York, NY, USA, 2001.

17. Karabacak, M.; Coruh, A.; Kurt, M. FT-IR, FT-Raman, NMR spectra, and molecular structure investigation of 2,3-dibromo- $N$-methylmaleimide: A combined experimental and theoretical study. J. Mol. Struct. 2008, 892, 125-131.

18. Sundaraganesan, N.; Illakiamani, S.; Saleem, H.; Wojciechowski, P.M.; Michalska, D. FT-Raman and FT-IR spectra, vibrational assignments and density functional studies of 5-bromo-2-nitropyridine. Spectrochim. Acta 2005, 61, 2995-3001.

19. Dennington, R.I.; Keith, T.; Millam, J.; Eppinnett, K.; Hovell, W.; Gilliland, R. Gauss View Version 3.09; Semichem, Inc.: Shawnee Mission, KS, USA, 2003.

20. Fleming, I. Frontier Orbitals and Organic Chemical Reactions; Wiley: London, UK, 1976.

21. O’Boyle, N.M.; Tenderholt, A.L.; Langer, K.M. cclib: A library for package-independent computational chemistry algorithms. J. Comput. Chem. 2008, 29, 839-845.

22. Krishnakumar, V.; Xavier, R.J. Normal coordinate analysis of 2-mercapto and 4,6-dihydroxy-2mercapto pyrimidines. Indian J. Pure Appl. Phys. 2003, 41, 597-601.

23. Dollish, F.R.; Fateley, W.G.; Bentley, F.F. Characteristic Raman Frequencies of Organic Compounds; Wiley: New York, NY, USA, 1997.

24. Varsanyi, G. Vibrational Spectra of Benzene Derivatives; Academic Press: New York, NY, USA, 1969.

25. Srivastava, A.; Singh, V.B. Theoretical and experimental studies of vibrational spectra of naphthalene and its cation. Indian J. Pure Appl. Phys. 2007, 45, 714-720. 
26. Lin-Vien, D.; Colthup, N.B.; Fateley, W.G.; Grasselli, J.G. The Handbook of Infrared Raman Characteristic Frequencies of Organic Molecules; Academic Press: Boston, MA, USA, 1991.

27. Karabacak, M.; Karaca, C.; Atac, A.; Eskici, M.; Karanfil, A.; Kose, E. Synthesis, analysis of spectroscopic and nonlinear optical properties of the novel compound:( $S)-N$-benzyl-1-phenyl-5(thiophen-3-yl)-4-pentyn-2-amine. Spectrochim. Acta A 2012, 97, 556-567.

28. Sourisseau, C.; Maraval, P. Optical and resonance Raman scattering study of two "bisazo" pigments derived from substituted benzene-2'-azonaphthols. J. Raman Spectrosc. 1994, 25, 477-488.

29. Barnes, A.J.; Majid, M.A.; Stuckey, M.A.; Gregory, P.; Stead, C.V. The resonance Raman spectra of Orange II and Para Red: Molecular structure and vibrational assignment. Spectrochim. Acta A 1985, 41, 629-635.

30. Silverstein, R.M.; Webster, F.X. Spectrometric Identification of Organic Compounds, 6th ed.; John Wiley, Inc.: New York, NY, USA, 2003.

31. Karabacak, M.; Kurt, M. The spectroscopic (FT-IR and FT-Raman) and theoretical studies of 5-bromo-salicylic acid. J. Mol. Struct. 2009, 919, 215-222.

(C) 2015 by the authors; licensee MDPI, Basel, Switzerland. This article is an open access article distributed under the terms and conditions of the Creative Commons Attribution license (http://creativecommons.org/licenses/by/4.0/). 